\title{
Optimization of Wheat Straw Pretreatment Process Parameters for Straw Mulch Mat
}

\author{
Ying Zhang, ${ }^{1, a}$ Dian-Ming Ju, , ${ }^{1, a}$ Zhen-lei Xing, ${ }^{b}$ Hao Zong, ${ }^{c}$ Long-Hai Li, , ${ }^{\text {a }}$ \\ Hai-Tao Chen, ${ }^{\mathrm{a}, *}$ Shuang Liu, ${ }^{\mathrm{a}}$ Rui Li, ${ }^{\mathrm{a}}$ and Sheng-Ming Zhang ${ }^{\mathrm{a}}$
}

\begin{abstract}
Straw mulch mat is a promising alternative to petroleum-based plastic mulching film. The straw pretreatment process parameters influence the mechanical properties of the mat. To explore the effect of pretreatment process parameters on physical properties of wheat straw mulch mat, a five-factor and five-level central composite design (CCD) methodology was studied. With response surface methodology (RSM) analysis, the effects of parameters (soaking water temperature, soaking time, processing speed, manufacturing temperature, and manufacturing pressure) on dry tensile index and wet tensile index of original film, and initial beating degree of the straw pulp were reported. The optimal technical parameters were optimized as soaking water temperature $90^{\circ} \mathrm{C}$, soaking time $1.5 \mathrm{~h}$, manufacturing pressure $1.5 \mathrm{MPa}$, processing speed 83.5 to $87.8 \mathrm{r} / \mathrm{min}$, and manufacturing temperature 95 to $100^{\circ} \mathrm{C}$. With the optimal condition, the dry tensile index, wet tensile index, and initial beating degree were higher than $8 \mathrm{~N} \cdot \mathrm{m} / \mathrm{g}, 4 \mathrm{~N} \cdot \mathrm{m} / \mathrm{g}$, and $17^{\circ} \mathrm{SR}$, respectively. With this pretreatment of raw materials, the wheat straw mulch mat would meet the demands of mechanical properties for agriculture mulching after adding chemical additives.
\end{abstract}

Keywords: Central composite design; Mulch; Wheat straw; Optimization

Contact information: a: Northeast Agricultural University, No. 600 Changjiang Road, Xiangfang District, Harbin, Heilongjiang Province, China; b: Shandong Ruibosi Tobacco Co., Ltd., Linyi, Shandong Province, China; c: Shandong Linyi Tobacco Co., Ltd., Linyi, Shandong Province, China;1: The first two authors contributed equally to this work, and the corresponding authors contributed equally to this paper;

*Corresponding authors: lilonghai@neau.edu.cn; htchen@neau.edu.cn

\section{INTRODUCTION}

Wheat straw is an abundantly available and renewable resource, and its cellulose content is higher than that of other types of crop straw (Alemdar and Sain 2008). In recent decades, wheat straw has been intensely studied in many fields (Yadav et al. 2017; Jin et al. 2018; Kamelnia et al. 2019), such as papermaking (Deykun et al. 2018) and plate manufacturing (Lu and Liu 2007; Chen et al. 2015; Puitel et al. 2017), functional cellulose and nanofibers, the research and development of composite materials (Chen et al. 2019; Kellersztein et al. 2019), and the refining bio-organic fertilizer and bioethanol production (Ihnat et al. 2015; Bian et al. 2019). Some studies have been applied in industries, thereby adding value to the wheat straw (Khan et al. 2015; Lv et al. 2016). Degradable mat products made with wheat straw and used in agricultural fields have been developed in recent years (Liu 2010; Han et al. 2011; Yuan et al. 2011; Li et al. 2013; Chen 2019; Li 2019). Because these products can inhibit weeds, improve grain output, and then biodegrade completely, this kind of crop straw fiber-based mulch has great potential to replace plastic mulching film (Haapala et al. 2014; Zhang et al. 2014; Haapala et al. 2015; Moore and 
Wszelaki.2019; Zhang et al. 2020). Straw fiber-based matting can be obtained by the traditional papermaking process with the pulp made by straw raw material and environmentally friendly functional additives.

In our group, a single screw extruder was designed to pretreat the wheat straw, which is a physical method of hot steam explosion with no ecological toxicity, in contrast to chemical treatment. After some experiments, the authors found that the physical properties of straw mulch film were directly influenced by the quality of pretreated straw, such as the water temperature for soaking wheat straw, soaking time, processing speed of the single screw, the manufacturing temperature, and pressure in the machine barrel. So how to optimize the physical pretreatment process parameters of raw straw is significant.

In this work, a central composite design (CCD) methodology was employed to design the pretreatment experiments. To optimize the best pretreatment parameters combination, response surface methodology (RSM) was adopted to optimize the processing parameters that affect the physical quality of wheat straw pulp.

\section{EXPERIMENTAL}

\section{Materials}

Ji Mai 26-type wheat straw was harvested in Shandong province of China in June 2018.

\section{Equipment}

The following equipment were used in the study: D200 straw pretreatment machine (25 to $120{ }^{\circ} \mathrm{C}$ working temperature, zero to $140 \mathrm{r} / \mathrm{min}$ processing speed) developed by Northeast Agricultural University of China, Harbin, China; ZT4-00 Valley beater (Zhongtong Test Equipment Co., Ltd., Xingping, China); ZJG-100 Schopper's beating degree instrument (Changchun Yueming Scientific Instruments Co., Ltd., Changchun, China); ZCX-A manual sheet former (Changchun Yueming Scientific Instruments Co., Ltd., Changchun, China); XFH-50CA Electrothermal pressure steam sterilizer (Zhejiang Xinfeng Medical Equipment Co., Ltd., Shaoxing, China); DRK101A paper product quality detector (Jinan Nake Industry and Trade Co., Ltd., Jinan, China); JA5003B electronic balance (0.001 g precision Shanghai Jingke Tianmei Scientific Instruments Co., Ltd., Shanghai, China); and a straw rubbing and cutting machine (Harbin Longmu Machinery Company, Harbin, China).

\section{Methods}

A central composite design (CCD) methodology with five factors of five levels was employed to design pretreatment experiments to optimize to study the effects and interaction of process factors. The five influencing factors considered were soaking water temperature $(A)$, soaking time $(B)$, processing speed $(C)$, manufacturing temperature $(D)$, and manufacturing pressure $(E)$. The dry tensile index $\left(y_{1}\right)$, wet tensile index $\left(y_{2}\right)$, and initial beating degree $\left(y_{3}\right)$, were selected as indicators. The ranges and levels of independent factors are shown in Table 1.

\section{Procedure}

In the first step, wheat straw was pulverized to a length of $150 \mathrm{~mm}$, which has been optimized by experiments. The pulverized straw was then soaked according to the soaking 
water temperature and soaking time listed in Table 2. The samples were processing with the D200 straw pretreatment machine, which was developed by Northeast Agricultural University of China (Harbin, China), using the corresponding processing speed, manufacturing temperature, and pressure. Then the initial beating degree of straw pulp was measured according to the Schopper-Riegler method, as per GB/T 3332 (2004), as soon as they were ready. The test piece of $70 \mathrm{~g} / \mathrm{m}^{2}$ grammage without chemical additives was made according to the Fast Cassette Method, as per GB/T 24326 (2009), which was used to measure the physical properties. The dry tensile index and wet tensile index of the diaphragm were measured according to the Tensile Strength Determination Method stated in GB/T 12914 (2008). Design-Expert software (Version 8.0.5b, State-Ease Inc., Minneapolis, MN, USA) was used for statistical data analysis to obtain the influence of factors on indexes.

Table 1. Experimental Factors Coded by Levels

\begin{tabular}{|c|c|c|c|c|c|}
\hline Level & $\begin{array}{c}\text { Soaking Water } \\
\text { Temperature } \\
\left({ }^{\circ} \mathrm{C}\right)\end{array}$ & $\begin{array}{c}\text { Soaking Time } \\
(\mathrm{h})\end{array}$ & $\begin{array}{c}\text { Processing } \\
\text { Speed } \\
\left(\mathrm{r} \cdot \mathrm{min}^{-1}\right)\end{array}$ & $\begin{array}{c}\text { Manufacturing } \\
\text { Temperature } \\
\left({ }^{\circ} \mathrm{C}\right)\end{array}$ & $\begin{array}{c}\text { Manufacturing } \\
\text { Pressure } \\
(\mathrm{MPa})\end{array}$ \\
\hline 2 & 126 & 2.5 & 95 & 100 & 2.5 \\
\hline 1 & 108 & 2 & 90 & 95 & 2 \\
\hline 0 & 90 & 1.5 & 85 & 90 & 1.5 \\
\hline-1 & 72 & 1 & 80 & 85 & 1 \\
\hline-2 & 54 & 0.5 & 75 & 80 & 0.5 \\
\hline
\end{tabular}

\section{RESULTS AND DISCUSSION}

\section{Experimental Data}

Thirty-six experiments were conducted according to the processing parameters in Table 2, and the experimental results are listed in Table 2.

\section{Influences of Factors on Dry Tensile Index}

The variance analysis results on dry tensile index are shown in Table 3 and indicate that the quadratic regression model could be used to describe the impact of factors on dry tensile index. The fitting equation was significant with F-value 30.60 and p-value less than 0.0001 under the confidence $\alpha=0.05$. The lack of fit with P-value 0.2826 was not significant relative to the pure error. The quadratic regression models could predict dry tensile index accurately according to the model Eq. 2,

$$
\begin{aligned}
y_{1}= & 8.71+0.54 A-0.88 C+0.90 D+0.18 E \\
& -0.33 A C-1.16 C D-0.29 D^{2}-0.30 E^{2}
\end{aligned}
$$

where $y_{1}$ represents the dry tensile index $(\mathrm{N} \cdot \mathrm{m} / \mathrm{g})$, and $A, B, C, D$, and $E$ indicate the soaking water temperature $\left({ }^{\circ} \mathrm{C}\right)$, soaking time $(\mathrm{h})$, processing speed $(\mathrm{r} / \mathrm{min})$, manufacturing temperature $\left({ }^{\circ} \mathrm{C}\right)$, and manufacturing pressure $(\mathrm{MPa})$, respectively.

By comparing the $\mathrm{p}$-values, it was found that processing speed and manufacturing temperature had the highest impact on the dry tensile index and the smallest $p$-value. This was followed by soaking water temperature, manufacturing pressure, and soaking time. The interactive effect between soaking water temperature and processing speed was 
significant, with a p-value of 0.0177 . And the interactive effect between processing speed and soaking water temperature is high significant as the p-value is less than 0.0001 .

Table 2. Experimental Data

\begin{tabular}{|c|c|c|c|c|c|c|c|c|}
\hline No. & $\begin{array}{l}\text { Soaking } \\
\text { Water } \\
\text { Temp. } \\
\left({ }^{\circ} \mathrm{C}\right)\end{array}$ & $\begin{array}{l}\text { Soak- } \\
\text { ing } \\
\text { Time } \\
\text { (h) }\end{array}$ & $\begin{array}{c}\text { Process- } \\
\text { ing } \\
\text { Speed } \\
\left(r \cdot \mathrm{min}^{-1}\right)\end{array}$ & $\begin{array}{l}\text { Manufac- } \\
\text { turing } \\
\text { Temp. } \\
\left({ }^{\circ} \mathrm{C}\right)\end{array}$ & $\begin{array}{l}\text { Manufac- } \\
\text { turing } \\
\text { Pressure } \\
\text { (MPa) }\end{array}$ & $\begin{array}{l}\text { Dry Tensile } \\
\text { Index } \\
y_{1}\left(\mathrm{~N} \cdot \mathrm{m} \cdot \mathrm{g}^{-1}\right)\end{array}$ & $\begin{array}{l}\text { Wet Tensile } \\
\text { Index } \\
y_{1}\left(\mathrm{~N} \cdot \mathrm{m} \cdot \mathrm{g}^{-1}\right)\end{array}$ & $\begin{array}{c}\text { Initial } \\
\text { Beating } \\
\text { Degree } \\
\left.\text { ( }{ }^{\circ} \mathrm{SR}\right)\end{array}$ \\
\hline 1 & 72 & 1 & 80 & 85 & 2 & 6.14 & 3.16 & 9.5 \\
\hline 2 & 108 & 1 & 80 & 85 & 1 & 6.99 & 3.04 & 11.1 \\
\hline 3 & 72 & 2 & 80 & 85 & 1 & 6.23 & 2.89 & 9.3 \\
\hline 4 & 108 & 2 & 80 & 85 & 2 & 7.58 & 3.61 & 11.4 \\
\hline 5 & 72 & 1 & 90 & 85 & 1 & 7.08 & 2.76 & 8.9 \\
\hline 6 & 108 & 1 & 90 & 85 & 2 & 7.76 & 3.29 & 10.3 \\
\hline 7 & 72 & 2 & 90 & 85 & 2 & 7.07 & 3.22 & 9.4 \\
\hline 8 & 108 & 2 & 90 & 85 & 1 & 7.57 & 3.16 & 11.4 \\
\hline 9 & 72 & 1 & 80 & 95 & 1 & 10.07 & 4.8 & 12.7 \\
\hline 10 & 108 & 1 & 80 & 95 & 2 & 12.02 & 5.76 & 21.6 \\
\hline 11 & 72 & 2 & 80 & 95 & 2 & 9.94 & 4.73 & 16.1 \\
\hline 12 & 108 & 2 & 80 & 95 & 1 & 11.96 & 5.55 & 16.4 \\
\hline 13 & 72 & 1 & 90 & 95 & 2 & 7.19 & 4.42 & 14.4 \\
\hline 14 & 108 & 1 & 90 & 95 & 1 & 6.89 & 3.28 & 13.2 \\
\hline 15 & 72 & 2 & 90 & 95 & 1 & 6.97 & 3.52 & 12.4 \\
\hline 16 & 108 & 2 & 90 & 95 & 2 & 6.99 & 3.33 & 14.1 \\
\hline 17 & 54 & 1.5 & 85 & 90 & 1.5 & 8.01 & 3.81 & 15.2 \\
\hline 18 & 126 & 1.5 & 85 & 90 & 1.5 & 10.97 & 5.22 & 20.8 \\
\hline 19 & 90 & 0.5 & 85 & 90 & 1.5 & 8.79 & 4.19 & 16.2 \\
\hline 20 & 90 & 2.5 & 85 & 90 & 1.5 & 9.06 & 4.31 & 15.4 \\
\hline 21 & 90 & 1.5 & 75 & 90 & 1.5 & 10.85 & 5.17 & 19.6 \\
\hline 22 & 90 & 1.5 & 95 & 90 & 1.5 & 7.03 & 3.35 & 9.6 \\
\hline 23 & 90 & 1.5 & 85 & 80 & 1.5 & 6.22 & 2.96 & 9.5 \\
\hline 24 & 90 & 1.5 & 85 & 100 & 1.5 & 9.25 & 4.4 & 18.5 \\
\hline 25 & 90 & 1.5 & 85 & 90 & 0.5 & 6.89 & 3.18 & 10.6 \\
\hline 26 & 90 & 1.5 & 85 & 90 & 2.5 & 8.53 & 4.16 & 16.2 \\
\hline 27 & 90 & 1.5 & 85 & 90 & 1.5 & 8.65 & 4.12 & 16.1 \\
\hline 28 & 90 & 1.5 & 85 & 90 & 1.5 & 8.01 & 3.81 & 17.5 \\
\hline 29 & 90 & 1.5 & 85 & 90 & 1.5 & 8.85 & 4.21 & 15.6 \\
\hline 30 & 90 & 1.5 & 85 & 90 & 1.5 & 8.28 & 3.94 & 13.1 \\
\hline 31 & 90 & 1.5 & 85 & 90 & 1.5 & 9.18 & 4.37 & 16.5 \\
\hline 32 & 90 & 1.5 & 85 & 90 & 1.5 & 9.63 & 4.59 & 17.9 \\
\hline 33 & 90 & 1.5 & 85 & 90 & 1.5 & 8.65 & 4.12 & 15.7 \\
\hline 34 & 90 & 1.5 & 85 & 90 & 1.5 & 8.01 & 3.81 & 14.4 \\
\hline 35 & 90 & 1.5 & 85 & 90 & 1.5 & 7.95 & 3.79 & 13.18 \\
\hline 36 & 90 & 1.5 & 85 & 90 & 1.5 & 8.28 & 3.94 & 15.1 \\
\hline
\end{tabular}


Table 3. Variance Analysis of Regression Model of Dry Tensile Index

\begin{tabular}{|c|c|c|c|c|c|}
\hline Source & $\begin{array}{c}\text { Sum of } \\
\text { Squares }\end{array}$ & $\begin{array}{c}\text { Degrees } \\
\text { of } \\
\text { Freedom }\end{array}$ & Mean Square & F-value & P-value \\
\hline Model & 74.52 & 8 & 8.28 & 30.60 & $<0.0001^{* *}$ \\
\hline A & 7.03 & 1 & 7.03 & 25.98 & $0.0005^{* *}$ \\
\hline C & 0.021 & 1 & 0.021 & 0.078 & $<0.0001^{* *}$ \\
\hline D & 19.57 & 1 & 19.57 & 72.31 & $<0.0001^{* *}$ \\
\hline E & 0.74 & 1 & 0.74 & 2.73 & 0.1106 \\
\hline AC & 1.74 & 1 & 1.74 & 6.41 & $0.0177^{*}$ \\
\hline CD & 21.37 & 1 & 21.37 & 78.97 & $<0.0001^{* *}$ \\
\hline$D^{2}$ & 2.74 & 1 & 2.74 & 10.13 & $0.0038^{* *}$ \\
\hline$E^{2}$ & 2.86 & 1 & 2.86 & 10.56 & $0.0032^{* *}$ \\
\hline Residual & 7.04 & 1 & 0.27 & & \\
\hline Lack of Fit & 4.27 & 26 & 0.25 & 0.82 & 0.6552 \\
\hline Pure Error & 2.76 & 17 & 0.31 & & \\
\hline Cor Total & 81.56 & 9 & & & \\
\hline
\end{tabular}

Notes: ${ }^{* *}$ represents highly significant $(p<0.01)$; and ${ }^{*}$ represents significant $(p<0.05)$.

3D response graphs between soaking water temperature and processing speed on dry tensile index are shown in Fig. 1a, which was obtained by varying the soaking water temperature from 54 to $126^{\circ} \mathrm{C}$ and processing speed from 75 to $95 \mathrm{r} / \mathrm{min}$, and holding other parameters constant (soaking time $1.5 \mathrm{~h}$, manufacturing temperature $90{ }^{\circ} \mathrm{C}$, manufacturing pressure $1.5 \mathrm{MPa}$ ). The dry tensile index was increasing with decreasing processing speed. This is because the wheat straw would spend more time steam exploding from the single screw extruder machine with low processing speed.

While in the condition of the high temperature and high pressure in machine barrel, there was more time that the wheat straw stayed in the machine barrel. As a consequence, more hydrolysable polysaccharides and volatile acids in wheat straw were dissolved. In addition, the lignocellulose structure of wheat straw was more flexible, which was the benefit of mechanical shearing by single screw and brooming after explosion. More branches after brooming sufficiently would enhance the binding force, which could enhance the stability of network structure of straw fiber mat.

The binding force is one of the most important factors influencing the dry tensile index of a straw fiber mat. It follows that decreasing the processing speed would increase the dry tensile index. However, the importance of this factor decreased with decreasing water temperature during soaking. This is mainly because the part of the extractives were not dissolved sufficiently when soaking wheat straw. The lignocellulose structure is still tough that needs more time and temperature to be broken by mechanical shearing. So the dry tensile index was decreasing with soaking water temperature, and the decreasing significance was progressively reduced with increasing processing speeding.

The highest dry tensile index was obtained at the lowest processing speed of 75 $\mathrm{r} / \mathrm{min}$ and highest soaking water temperature of $126^{\circ} \mathrm{C}$. The minimum value of dry tensile index value was obtained at the processing speed of $95 \mathrm{r} / \mathrm{min}$ and soaking water temperature of $54^{\circ} \mathrm{C}$. 


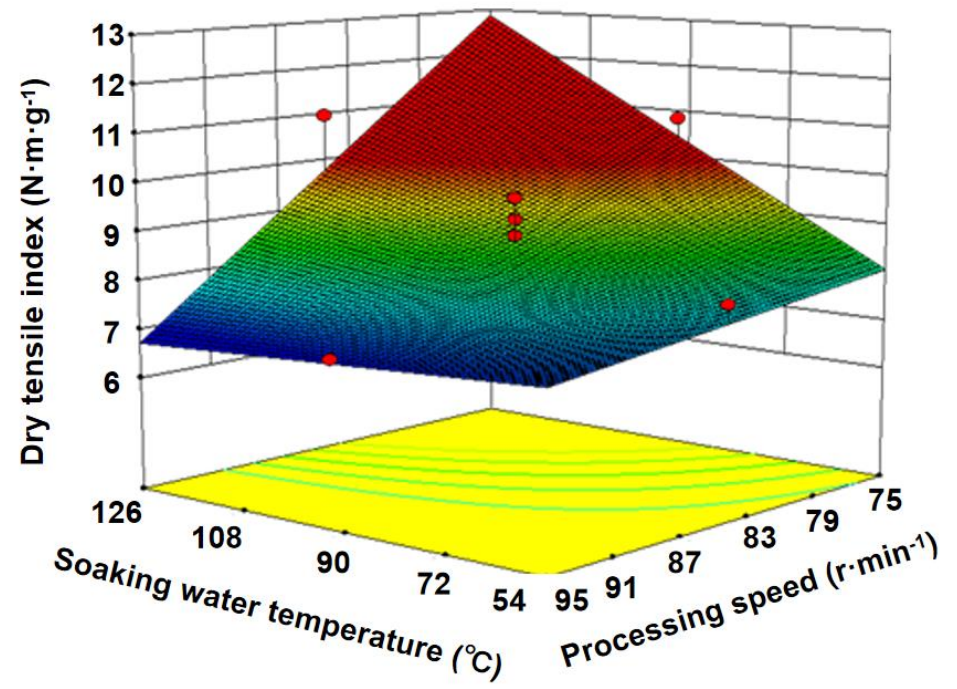

(a) Influence of soaking water temperature and processing speed on dry tensile index

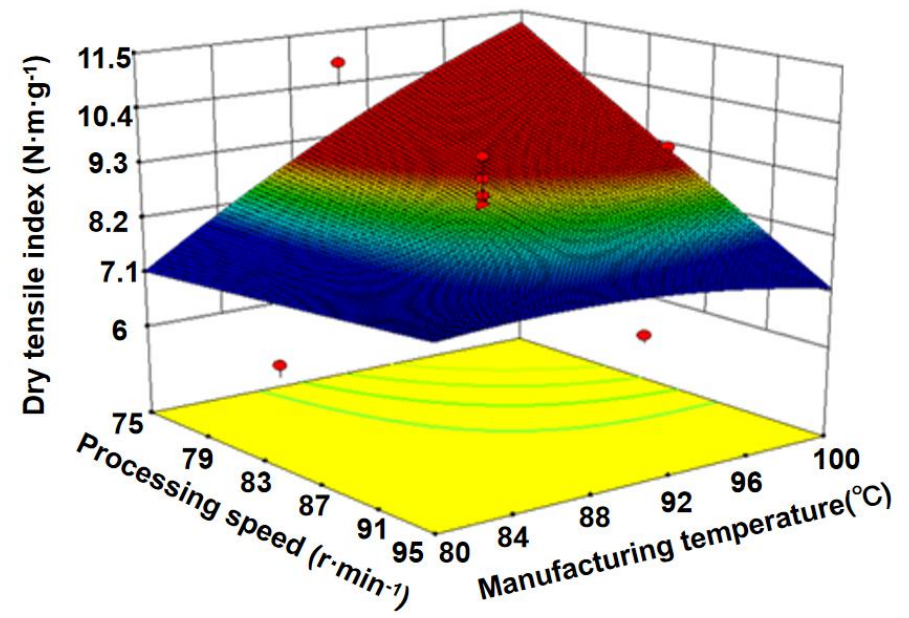

(b) Influence of processing speed and manufacturing temperature on dry tensile index

Fig. 1. Response surface plot of factors affecting dry tensile index

The interaction graph between the parameters of processing speed and manufacturing temperature on dry tensile index is shown in Fig. 1b, which was obtained by holding the three other parameters constant (soaking water temperature $90{ }^{\circ} \mathrm{C}$, soaking time $1.5 \mathrm{~h}$, manufacturing pressure $1.5 \mathrm{MPa}$ ). The dry tensile index increased with decreasing processing speed at high manufacturing temperature. This is mainly because with more time of wheat straw staying in the machine barrel at high temperature, there was breakdown of the long-chain molecules to become short chain molecules by mechanical shearing. After steam explosion, adequate brooming was beneficial to fiber crosslinking to enhance the dry tensile index. However, at the low manufacturing temperature the dry tensile index showed no increase. This is mainly because the wheat straw was crushed only by mechanical shearing without the help of high manufacturing temperature. The structure of lignocellulose was tough enough so that it did not broom adequately to decrease the dry tensile index. As a consequence, the dry tensile index also increased with increasing 
manufacturing temperature at low processing speed. The highest dry tensile index was obtained at the lowest processing speed of $75 \mathrm{r} / \mathrm{min}$ and highest manufacturing temperature of $100{ }^{\circ} \mathrm{C}$.

\section{Influences of Factors on Wet Tensile Index}

The variance analysis results for wet tensile index (Table 4) indicate that the quadratic regression model could be used to describe the impact of factors on dry tensile index. The fitting equation was significant with F-value 17.41 and p-value less than 0.0001 under the confidence $\alpha=0.05$. The lack of fit with p-value 0.1648 was not significant relative to the pure error. The quadratic regression models could predict dry tensile index accurately according to the model equation 3 .

$$
\begin{aligned}
y_{2}= & 4.14+0.18 A-0.42 C+0.55 D+0.19 E \\
& -0.20 A C-0.38 C D-0.15 D^{2}-0.15 E^{2}
\end{aligned}
$$

In Eq. 3, $y_{2}$ represents the wet tensile index $(\mathrm{N} \cdot \mathrm{m} / \mathrm{g})$ and $A, B, C, D$, and $E$ indicate the soaking water temperature $\left({ }^{\circ} \mathrm{C}\right)$, soaking time $(\mathrm{h})$, processing speed $(\mathrm{r} / \mathrm{min})$, manufacturing temperature $\left({ }^{\circ} \mathrm{C}\right)$, and manufacturing pressure $(\mathrm{MPa})$, respectively.

By comparing the $\mathrm{p}$-values, it was found that processing speed and manufacturing temperature had the highest impact on the wet tensile index, with the smallest p-value. This was followed by soaking water temperature, manufacturing pressure, and soaking time. The interactive effect between soaking water temperature and processing speed was significant as the p-value is 0.0225 . The interactive effect between processing speed and soaking water temperature was highly significant, with a p-value is less than 0.0001 .

Table 4. Variance Analysis of Regression Model of Wet Tensile Index

\begin{tabular}{|c|c|c|c|c|c|}
\hline Source & $\begin{array}{c}\text { Sum of } \\
\text { Squares }\end{array}$ & $\begin{array}{c}\text { Degrees } \\
\text { of } \\
\text { Freedom }\end{array}$ & Mean Square & F-value & P-value \\
\hline Model & 17.47 & 8 & 1.94 & 17.41 & $<0.0001^{\star *}$ \\
\hline A & 0.78 & 1 & 0.78 & 7.04 & $0.0134^{*}$ \\
\hline C & 4.33 & 1 & 4.33 & 38.89 & $<0.0001^{* *}$ \\
\hline D & 7.19 & 1 & 7.19 & 64.54 & $<0.0001^{* *}$ \\
\hline E & 0.84 & 1 & 0.84 & 7.50 & $0.0110^{*}$ \\
\hline AC & 0.66 & 1 & 0.66 & 5.89 & $0.0225^{*}$ \\
\hline CD & 2.27 & 1 & 2.27 & 20.32 & $0.0001^{\star *}$ \\
\hline$D^{2}$ & 0.69 & 1 & 0.69 & 6.16 & $0.0199^{*}$ \\
\hline$E^{2}$ & 0.71 & 1 & 0.71 & 6.37 & $0.0181^{*}$ \\
\hline Residual & 2.90 & 26 & 0.11 & & \\
\hline Lack of Fit & 2.27 & 17 & 0.13 & 1.90 & 0.1648 \\
\hline Pure Error & 0.63 & 9 & 0.070 & & \\
\hline
\end{tabular}

Notes: ${ }^{* \star}$ represents highly significant $(P<0.01)$; and ${ }^{\star}$ represents significant $(P<0.05)$

$3 \mathrm{D}$ interaction response graphs between soaking water temperature and processing speed on wet tensile index (Fig. 2a) was obtained by changing the soaking water temperature from 72 to $126^{\circ} \mathrm{C}$ and processing speed from 75 to $95 \mathrm{r} / \mathrm{min}$ but holding three other parameters constant (soaking time $1.5 \mathrm{~h}$, manufacturing temperature $90{ }^{\circ} \mathrm{C}$, manufacturing pressure 1.5 MPa). It was shown that the wet tensile index was increased 
with increasing soaking water temperature at low processing speed. This can be mainly attributed to the fact that hydrolysable polysaccharides and volatile acids in wheat straw were more easily dissolved with high soaking temperature, which caused the lignocellulose structure of wheat straw to become soft and to be crushed by mechanical shearing. With more crushing time of the wheat straw with single screw, more branches after brooming were obtained. So, at low processing speed, the dry tensile index increased significantly with increasing soaking water temperature. The increase was not significant at high process speed, due to insufficient crushing. The wet tensile index value increased with decreasing processing speed at high soaking water temperature. However, the increase was not significant at low soaking water temperature, which was mainly attributed to the fact that part of the hydrolysate was not dissolved at low temperature. In addition, the wheat straw could not be crushed sufficiently, despite the lower processing speed. The highest wet tensile index was obtained at the lowest processing speed of $75 \mathrm{r} / \mathrm{min}$ and highest soaking water temperature of $126^{\circ} \mathrm{C}$. The minimum value of dry tensile index value was observed at the processing speed of $95 \mathrm{r} / \mathrm{min}$ and soaking water temperature of $126^{\circ} \mathrm{C}$.

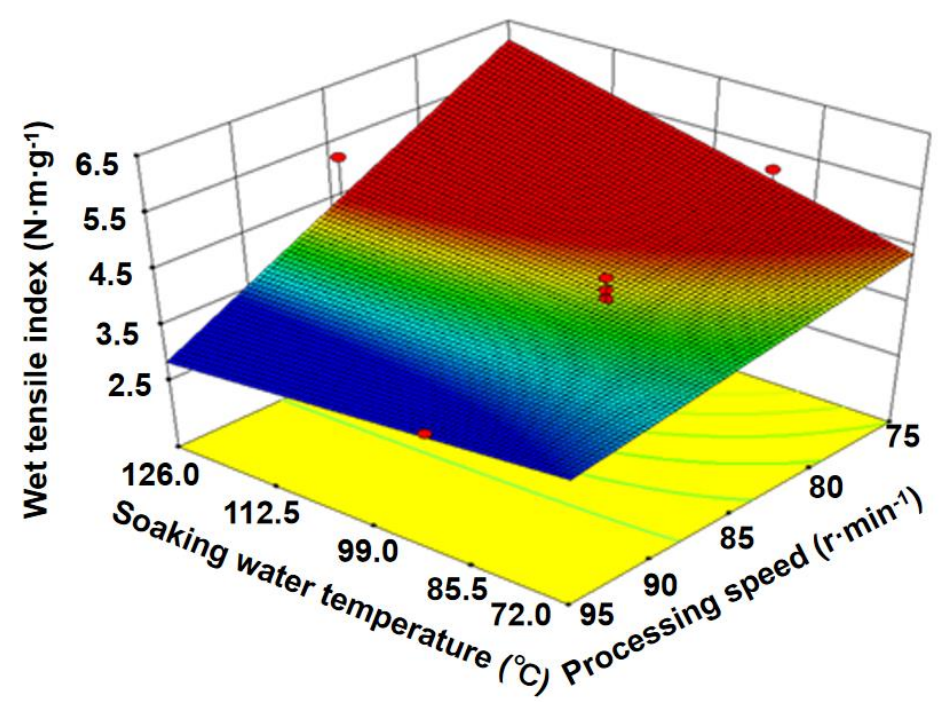

(a) Influence of soaking water temperature and processing speed on wet tensile index

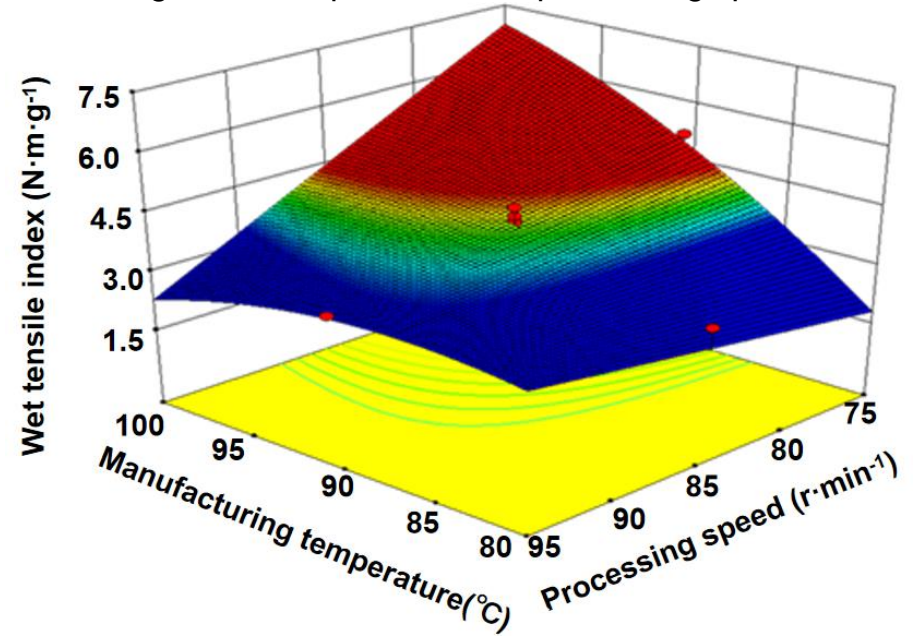

(b) Influence of processing speed and manufacturing temperature on wet tensile index

Fig. 2. Response surface plot of factors affecting wet tensile index 
The interaction response for wet tensile index between the parameters of processing speed and manufacturing temperature is shown in Fig. 2b, while keeping three other parameters constant (soaking water temperature $90{ }^{\circ} \mathrm{C}$, soaking time $1.5 \mathrm{~h}$, manufacturing pressure 1.5 $\mathrm{MPa}$ ). The wet tensile index increased with increasing manufacturing temperature at low processing speed. This is mainly because there was enough time for wheat straw to be crushed by single screw in machine barrel, and the long chain molecule chain was easily shortened, which was beneficial for achieving adequate brooming after steam explosion to enhance the wet tensile index. However, at the high processing speed, the increasing of wet tensile index was not significant. This is mainly because the wheat straw needs more time to be crushed sufficiently, despite the high manufacturing temperature. The highest wet tensile index was obtained at the lowest processing speed of $75 \mathrm{r} / \mathrm{min}$ and highest manufacturing temperature of $100^{\circ} \mathrm{C}$.

\section{Influence Factors on Initial Beating Degree}

Linear regression models were used to analyze the relative significance of initial beating degree according to the experimental results. The variance analysis results in Table 5 indicated that the model was significant with F-value 8.74 and p-value less than 0.0001 under the confidence $\alpha=0.05$. The lack of fit with p-value 0.0736 was not significant relative to the pure error. This means the quadratic regression models for the dry tensile index gave a good prediction, and the model equation is shown in Eq. 3,

$$
y_{3}=14.14+1.17 A-1.42 C+2.4 D+0.94 E
$$

where $y_{3}$ represents the initial beating degree ( $\left.{ }^{\circ} \mathrm{SR}\right)$, and $A, C, D$, and $E$ indicate the soaking water temperature $\left({ }^{\circ} \mathrm{C}\right)$, processing speed $(\mathrm{r} / \mathrm{min})$, manufacturing temperature $\left({ }^{\circ} \mathrm{C}\right)$, and manufacturing pressure $(\mathrm{MPa})$, respectively.

By comparing the p-values, we could identify the impact degree of parameters on initial beating degree. As the p-value was less than 0.0001, manufacturing temperature had the highest impact, followed by processing speed, soaking water temperature, manufacturing pressure, and soaking time. The same conclusion could be reached by comparing the regression coefficients.

Table 5. Variance Analysis of Regression Model of Initial Beating Degree

\begin{tabular}{|c|c|c|c|c|c|}
\hline Source & $\begin{array}{c}\text { Sum of } \\
\text { Squares }\end{array}$ & $\begin{array}{c}\text { Degrees of } \\
\text { Freedom }\end{array}$ & Mean Square & F-value & P-value \\
\hline Model & 240.68 & 5 & 48.14 & 8.74 & $<0.0001^{\star *}$ \\
\hline A & 32.67 & 1 & 32.67 & 5.93 & $0.0211^{*}$ \\
\hline B & 0.33 & 1 & 0.33 & 0.059 & 0.8093 \\
\hline C & 48.17 & 1 & 48.17 & 8.74 & $0.0060^{* *}$ \\
\hline D & 138.24 & 1 & 138.24 & 25.09 & $<0.0001^{* *}$ \\
\hline E & 21.28 & 1 & 21.28 & 3.86 & $0.0587^{*}$ \\
\hline Residual & 165.30 & 30 & 5.51 & & \\
\hline Lack of Fit & 141.62 & 21 & 6.74 & 2.56 & 0.0736 \\
\hline Pure Error & 23.68 & 9 & 2.63 & & \\
\hline Cor Total & 405.98 & 35 & & & \\
\hline
\end{tabular}

Notes: ** represents highly significant $(P<0.01)$;and *represents significant $(P<0.05)$ 
Figure 3 shows the effect of parameters affecting initial beating degree. Initial beating degree was positively correlated with soaking water temperature (Fig. 3a), manufacturing temperature (Fig. 3c), and manufacturing pressure (Fig. 4d), but negatively correlated with processing speed (Fig. 3b). It was found that both manufacturing temperature and processing speed were the most influential factors on initial beating degree. The figures dealing with one factor at a time clearly revealed that high soaking temperature led to greater dissolution of part of the wheat straw components, and low processing speed and high manufacturing temperature were beneficial for wheat straw to be crushed with mechanical shearing. High manufacturing pressure could help to achieve sufficient brooming of the wheat straw.
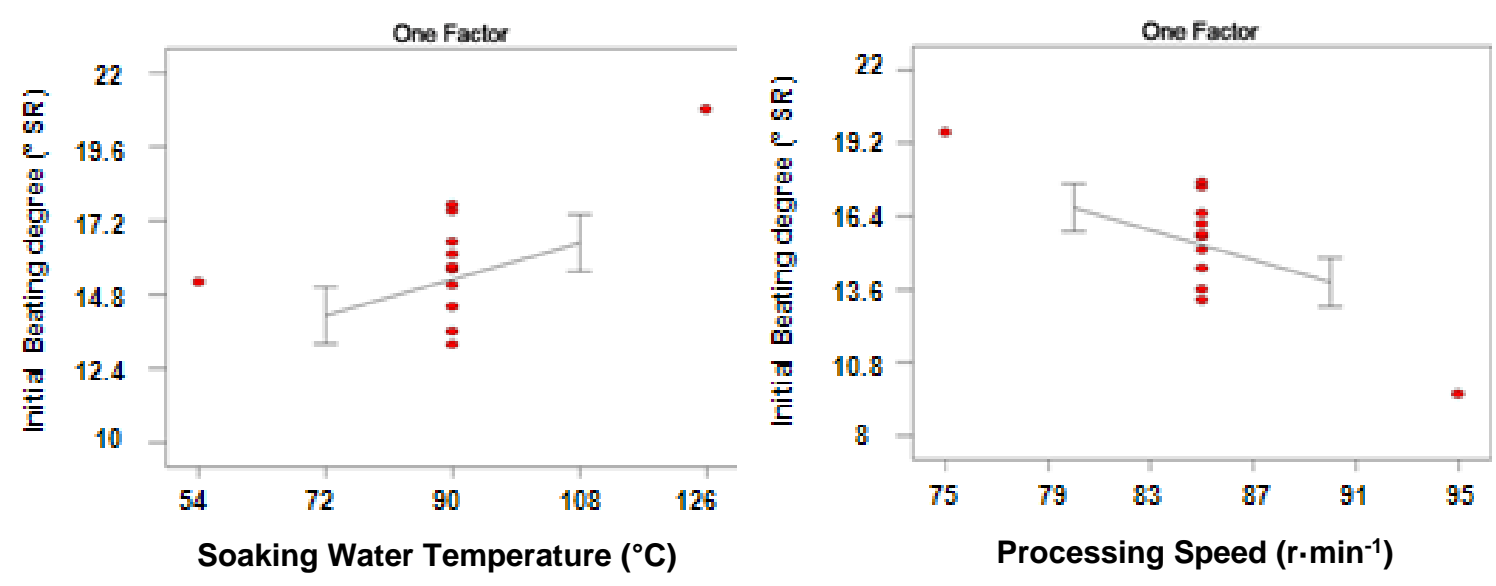

(a) Soaking Water Temperature

(b) Processing Speed
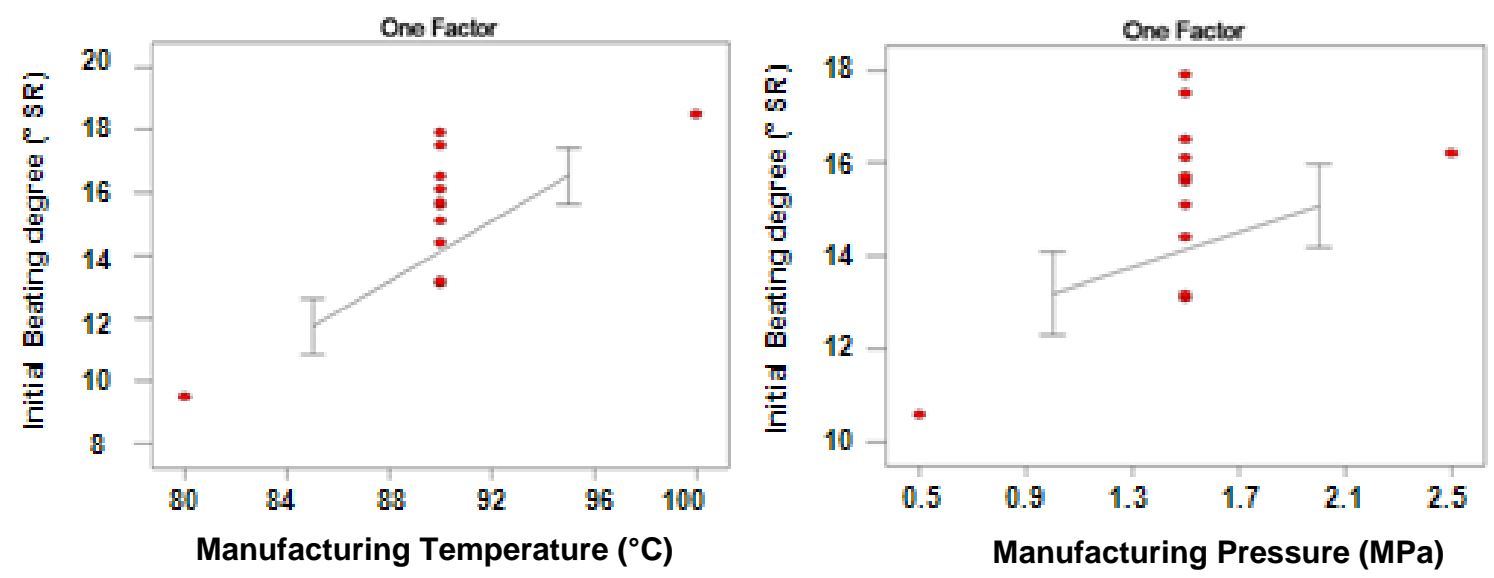

(c) Manufacturing Temperature

(d) Manufacturing Pressure

Fig. 3. Effects of Four Variables on Initial Beating Degree: (a) Soaking Water Temperature, (b) Processing Speed, (c) Manufacturing Temperature, and (d) Manufacturing Pressure.

\section{Optimization of Parameters}

The wheat straw pretreatment process for straw mulch mat was optimized. For meeting the demands of dry tensile index, wet tensile index, and initial beating degree, the soaking water temperature $90^{\circ} \mathrm{C}$, soaking time $1.5 \mathrm{~h}$, and manufacturing pressure $1.5 \mathrm{MPa}$ were selected by considering the economy, ecological balance, and possibility of subsequent treatment. Based on the design model and the constraints described above, 
Design-Expert software version 8.0.5b was used to numerical optimize by considering the five independent variables and the three responses. The range of manufacturing temperature and processing speed were optimized as shown in Fig. 4. Under the optimum conditions, the dry tensile strength is higher than $8 \mathrm{~N} \cdot \mathrm{m} / \mathrm{g}$, the wet tensile strength was higher than $4 \mathrm{~N} \cdot \mathrm{m} / \mathrm{g}$, and the initial beating degree was larger than $17^{\circ} \mathrm{SR}$.

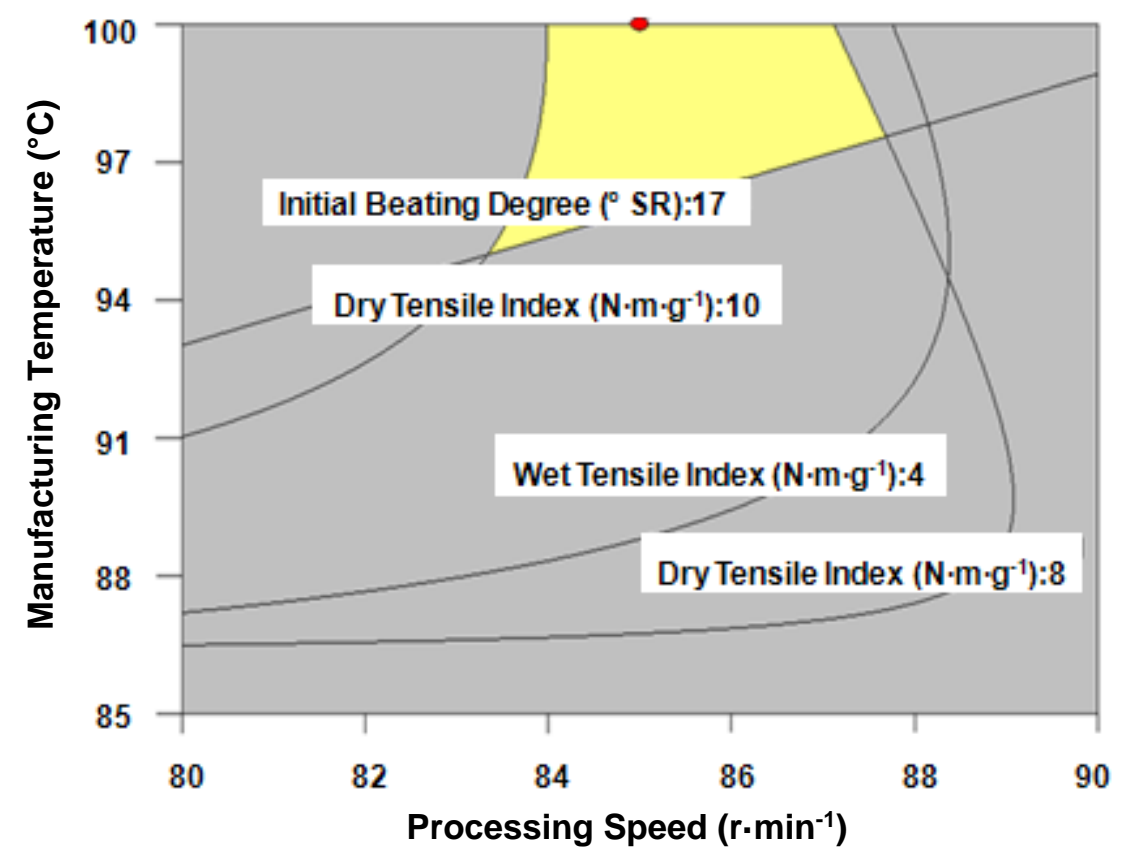

Fig. 4. Optimum analysis of technology parameters

\section{CONCLUSIONS}

In this work, wheat straw pretreatment process for straw mulch film was optimized using the RSM method. The result indicates that soaking water temperature, processing speed, and manufacturing temperature are the main factors influencing the physical properties of mulch mat products. The optimized process parameters were found to be soaking water temperature $90{ }^{\circ} \mathrm{C}$, soaking time $1.5 \mathrm{~h}$, manufacturing pressure $1.5 \mathrm{MPa}$, processing speed 83.5 to $87.8 \mathrm{r} / \mathrm{min}$, and manufacturing temperature 95 to $100{ }^{\circ} \mathrm{C}$, which meets the demands of dry tensile strength $(8 \mathrm{~N} \cdot \mathrm{m} / \mathrm{g})$, wet tensile strength $(4 \mathrm{~N} \cdot \mathrm{m} / \mathrm{g})$, and initial beating degree $\left(17^{\circ} \mathrm{SR}\right)$.

\section{ACKNOWLEDGMENTS}

The authors acknowledge funds from the National Natural Science Foundation Youth Fund of China (31701311), the Science and Technology Project of Shandong Tobacco Monopoly Bureau (Company) in 2018, and the National Key Research and Development Plan (2018YFD0201004). 


\section{REFERENCES CITED}

Alemdar, A., and Sain, M. (2008). "Isolation and characterization of nanofibers from agricultural residues - Wheat straw and soy hulls," Bioresource Technology 99(6), 1664-1671. DOI: 10.1016/j.biortech.2007.04.029

Bian, H., Gao, Y., Luo, J., Jiao, L., Wu, W. B., Fang, G. G., and Dai, H. Q. (2019). "Lignocellulosic nanofibrils produced using wheat straw and their pulping solid residue: From agricultural waste to cellulose nanomaterials," Waste Management 91, 1-8. DOI: 10.1016/j.wasman.2019.04.052

Chen, K. F., Tian, X. J., Wang, B., and Li, J. (2015). "Optimization and evaluation of advanced technologies applied to pulp and papermaking using agricultural straw," Journal of South China University of Technology (Natural Science Edition) 43(10), 122-130. DOI: 1000-565X(2015)43:10<122:LYNYJG>2.0.TX;2-3

Chen, P. C. (2019). Study on Preparation and Properties of Jute Mulching Film by Wetlaying Nonwoven Process, Master's Thesis, Donghua University, Shanghai, China.

Chen, Y. P., Dang, B. K., Jin, C. D., and Sun, Q. F. (2019). "Processing lignocellulosebased composites into an ultrastrong structural material," ACS Nano 13(1), 371-376. DOI: 10.1021/acsnano.8b06409

Deykun, I., Halysh, V., and Barbash, V. (2018). "Rapeseed straw as an alternative for pulping and papermaking," Cellulose Chemistry and Technology 52(9-10), 833-839.

GB/T3332 (2004). "Pulps - Determination of beating degree (Schopper-Riegler method)," Standardization Administration of China, Beijing, China.

GB/T12914 (2008). "Paper and board-Determination of tensile properties," Standardization Administration of China, Beijing, China.

GB/T24325 (2009). "Pulps - Laboratory beating - Valley beater method," Standardization Administration of China, Beijing, China.

GB/T24326 (2009). "Pulps - Preparation of laboratory sheets for physical testing Rapid-Köthen method," Standardization Administration of China, Beijing, China.

Haapala, T., Palonen, P., Korpela, A., and Jukka, A. (2014). "Feasibility of paper mulches in crop production: A review," Agricultural and Food Science 23(1), 60-79. DOI: $10.23986 /$ afsci.8542

Haapala, T., Palonen, P., Tamminen, A., and Ahokas, J. (2015). "Effects of different paper mulches on soil temperature and yield of cucumber (Cucumis sativus L.) in the temperate zone," Agricultural and Food Science 24(1), 52-58. DOI:

10.23986/afsci.47220

Han, Y. J., Chen, H. T., Liu, L.X., and Li, H. (2011). "Optimization of technical parameters for making mulch from rice straw fiber," Transactions of the Chinese Society of Agricultural Engineering (Transactions of the CSAE) 27(3), 242-247.DOI: 1002-6819(2011)27:3<242:SDJGXW>2.0.TX;2-U

Ihnat, V., Lubke, H., Boruvka, V., Babiak, M., and Schwartz, J. (2015). "Straw pulp as a secondary lignocellulosic raw material and its impact on properties of insulating fiberboards. Part II. Preparation of insulated fiberboards with straw fiber content," Wood Research 60(2), 235-245.

Jin, Q., Yang, L. C., Poe, N., and Huang, H. B. (2018). "Integrated processing of plantderived waste to produce value-added products based on the biorefinery concept," Trends In Food Science \& Technology 74, 119-131. DOI: 10.1016/j.tifs.2018.02.014

Kamelnia, E., Divsalar, A., Darroudi, M., Yaghmaei, P., and Sadri, K. (2019). "Production of new cellulose nanocrystals from Ferula gummosa and their use in 
medical applications via investigation of their biodistribution," Industrial Crops and Products 139, Article ID 111538. DOI: 10.1016/j.indcrop.2019.111538

Kellersztein, I., Shani, U., Zilber, I., and Dotan, A. (2019). "Sustainable composites from agricultural waste: The use of steam explosion and surface modification to potentialize the use of wheat straw fibers for wood plastic composite industry," Polymer Composites 40(S1), E53-E61. DOI:10.1002/pc.24472

Khan, N. A., Hussain, S., Ahmad, N., Alam, S., Bezabhi, M., Hendriks, W. H., Yu, P., and Cone, J. W. (2015). "Improving the feeding value of straws with Pleurotus ostreatus," Animal Production Science 55(2), 241-245. DOI: 10.1071/AN14184

Li, H. (2019). Preparation and Properties of Degradable Cellulose-mulching Films, Master's Thesis, Qilu University of Technology, Jinan, China.

Li, L.X., Ji, W. Y., Chen, H. T., and Zhou, C. (2013). "Technology optimization for manufacturing biodegradable mulch using soybean straw fiber," Transactions of the Chinese Society of Agricultural Engineering (Transactions of the CSAE) 29(14), 220226. DOI: 1002-6819(2013)29:14<220:DDJGXW>2.0.TX;2-9

Liu, L. X. (2010). Experimental Study on Manufacturing Technology and Performance of Biogas Residue Mulching for Dry Farming, Master's Thesis, Northeast Agricultural University, Harbin, China.

Lu, Y. H., and Liu, Z. (2007). "Optimization of acid-catalytic ethanol pulping of wheat straw using response surface methodology," Transactions of China Pulp and Paper 22(2), 13-17. DOI: 1000-6842(2007)22:2<13:XYMFYH>2.0.TX;2-B

Lv, E. M., Xia, W.Y., Tang, M. X., and Pu, Y. W. (2016). "Preparation of an efficient oil-spill adsorbent based on wheat straw," BioResources 12(1), 296-315. DOI: 10.15376/biores.12.1.296-315

Moore, J. C., and Wszelaki, A. L. (2019). "The use of biodegradable mulches in pepper production in the southeastern United States," HortScience 54(6), 1031-1038. DOI: 10.21273/HORTSCI13942-19

Puitel, A. C., Moisei, N., Tofanica, B. M., and Gavrilescu, D. (2017). “Turning wheat straw in a sustainable raw material for paper industry," Environmental Engineering and Management Journal 16(4), 1027-1032. DOI: 10.30638/eemj.2017.104

Yadav, M., Moreau, R., Hicks, K., and Kale, M. (2017). "Functional cellulosic arabinoxylan fiber from agricultural biomass," in: Abstracts of Papers of the American Chemical Society, American Chemical Society, Washington, DC, USA, pp. 253-402.

Yuan, Q. S., Chen, H. T., Han, Y. J., Li, L.X., and Huang, Z.H. (2011). "Optimization of technology parameters of making mulch from corn straw fiber," Heilongjiang Pulp and Paper 39(2), 1-5.

Zhang, Y., Chen, H. R., Dun, G. Q., Han, Y. J., and Chen, H. T. (2014). "Study on the stalk fiber films mulching cultivation green pepper," Journal of Northeast Agricultural University 45(11), 95-100. DOI: 10059369(2014)45:11<95:JGXWDM>2.0.TX;2-W

Zhang, Y., Chen, H. T., Liu, S., Rokayya, S., and He, Y. Y. (2020). “Optimization of process parameters for preparing straw fiber from corn stalk rind," BioResources 15(1), 923-934. DOI: 10.15376/biores.15.1.923-934

Article submitted: June 26, 2020; Peer review completed: October 18, 2020; Revisions accepted: April 7, 2021; Published: April 12, 2021.

DOI: 10.15376/biores.16.2.3827-3839 